\title{
PERFORMANCE ANALYSIS OF WEB-BASED RELATIVE AND PRECISE POINT POSITIONING TECHNIQUES WITH DIFFERENT SATELLITE VISIBILITY CONDITIONS
}

\author{
Müge Albayrak ${ }^{1,2}$ - ORCID: 0000-0001-6705-4044 \\ Bahattin Erdoğan ${ }^{3}$ - ORCID: 0000-0002-8060-9208 \\ Halil Erkaya ${ }^{4}$ - ORCID: 0000-0001-5098-1490 \\ ${ }^{1}$ Istanbul Technical University, Department of Geomatics Engineering, Istanbul, Turkey. \\ E-mail: albayrakmug@itu.edu.tr \\ ${ }^{2}$ The Ohio State University, School of Earth Sciences, Columbus, OH, USA. \\ E-mail: albayrak.6@osu.edu \\ ${ }^{3}$ Yildiz Technical University, Department of Geomatics Engineering, Istanbul, Turkey. \\ E-mail: berdogan@yildiz.edu.tr \\ ${ }^{4}$ Istanbul Okan University, Department of Geomatics Engineering, Istanbul, Turkey. \\ E-mail: halil.erkaya@okan.edu.tr
}

Received in $10^{\text {th }}$ October 2019

Accepted in $15^{\text {th }}$ October 2019

\begin{abstract}
:
The Global Navigation Satellite System (GNSS) is used for precise positioning applications, such as surveying and geodesy. The aim of the present work is to evaluate the effectiveness of web-based relative positioning (RP) and precise point positioning (PPP) GNSS post-processing services using measurements of different satellite visibility obstacles. Within this framework, static GNSS observations were conducted at three control benchmarks selected taking the impact of natural and human-made obstacles on satellite signals into consideration. 3 hours of static GNSS observations in Istanbul, Turkey were repeatedly obtained from three control BMs over six days and were evaluated through two RP (AUSPOS, OPUS) and three PPP (CSRS-PPP, Magic-PPP, GAPS-PPP) web-based GNSS post-processing services. The 6-day average of the three control benchmark coordinates computed using the Bernese GPS software v5.0, and were accepted as true results. They were compared to the local coordinates acquired through the RP and PPP web-based GNSS post-processing services. The different satellite visibility conditions were found to have significant effects on the GNSS point positioning solutions. We also found that web-based GNSS post-processing services provide easy and effective solutions for geodetic positioning applications.
\end{abstract}

Keywords: GNSS; Precise point positioning (PPP); Relative positioning; Web-based GNSS post-processing services; Static GNSS measurement.

How to cite this article: ALBAYRAK, M; ERDOĞAN, B.; ERKAYA, H. Performance analysis of web-based relative and precise point positioning techniques with different satellite visibility conditions. Bulletin of Geodetic Sciences. 26(1): e2020003, 2020 


\section{Introduction}

Today, satellite-based positioning systems are employed efficiently to obtain highly accurate spatial information. These systems are generally known as the Global Navigation Satellite System (GNSS) and encompass various applications (Hofmann-Wellenhof et al. 2007). The GNSS has created a dynamic platform, particularly for geodetic positioning research, and has lent new impetus to the land-surveying sector. The momentum gained during this rapid technological change and development contributes to a more practical perspective for analysis of: geodetic and cadastral applications, surveys for engineering purposes, terrestrial, mobile and airborne light detection and ranging (LIDAR) research, determination of crustal movements, hydrographic surveys, deformations monitoring, and geographic information system (GIS), among others (Rizos 2017; Langley et al. 2017).

Apart from these comprehensive applications, there are many possible GNSS positioning measurements modes which vary in terms of complexity, precision, and accuracy based on user or program needs (Langley et al. 2017). To improve GNSS precision and accuracy for measurement and modelling, it is important to understand the causes of station dependent errors, such as antenna phase variations and multipath effects (Wübbena et al. 2000; Wübbena et al. 2006; Hirt et al. 2010).

Although there is an increasing variety of GNSS applications, these techniques are still based either on relative or absolute position determination principles. Taking both relative positioning (RP) and precise point positioning (PPP) principles into consideration, especially in post-processing, it is necessary for users to have professional experience in both GNSS data processing and analysis software usage. Therefore, the scientific and commercial data evaluation software must meet those users' requirements. Appropriate software selection depends upon the purpose of the research (e.g., deformation) and features of the network (e.g., baseline length). However, the main consideration is that users need a significant amount of time to gain a comprehensive understanding of the subject. These scientific software packages are not readily accessible to inexperienced users (Ebner and Featherstone 2008). Furthermore, because license fees for these commercial software packages are very high, purchases should be considered carefully (Tsakiri 2008).

Apart from scientific and commercial software have traditionally used by professionals, in recent years several web-based (WB) GNSS processing and data evaluation services have been developed for less-skilled users by various institutions. Even basic GNSS positioning and data evaluation application users can benefit from these services. They are user-friendly because they are backed up by scientific software, and most of these services are open-access. Additionally, the development of WB positioning services is a current research area for researchers working in the GNSS positioning and data evaluation field.

The main aim of the present work is to evaluate static GNSS observations using Bernese GPS software v5.0, two RP (AUSPOS, OPUS) and three PPP (CSRS-PPP, Magic-PPP, GAPS) WB post-processing services. Observations for this analysis were conducted at three specifically-chosen ground benchmarks (BMs) in Istanbul, Turkey. A brief description of the RP and PPP, including a comparison of the WB RP and PPP techniques, is given in Section 2. Section 3 describes the features of the collected static GPS observation data from the field. The results of the Bernese GPS software v5.0 and WB GNSS services and comparison are presented in Section 4, followed by the conclusion in Section 5. 


\section{The relative positioning versus precise point positioning techniques}

GNSS observables are ranges deduced from measured time or phase differences based on a comparison between received signals and receiver-generated signals. The code ranges' accuracy is measured in meters, whilst the carrier phases' accuracy is in the millimetre range. Specific receiver technology or smoothing techniques can be used to improve the code ranges' accuracy. While the code ranges are largely unambiguous, phase ranges are weakened by the fact that they are ambiguous by an integer number of full wavelengths (Hofmann-Wellenhof et al. 2007). To obtain the high-accuracy coordinates for satellite-based positioning, the determination of the phase ambiguities is a critical requirement.

Conventionally, most of the professional GNSS users utilise the RP technique to obtain highly accurate coordinate. However, this technique has some disadvantages compared to the absolute positioning technique, such as the fact that a minimum of two or more GNSS receivers must be used, and the true coordinates of the reference stations must be known (Héroux and Kouba 2001; Gao and Chen 2004). In addition, the increase in the distance between the reference station (base) and rover station reduces the accuracy of the position.

The RP approach has changed over the last few decades. Observations no longer require at least two GNSS receivers and instead can be obtained using just one, because of the permanent reference receiver networks' (Continuously Operating Reference Station [CORS]) control point which is associated with a single GNSS receiver. The strategy for setting up CORS networks to process GNSS data using the RP technique has important advantages. These networks, which are set up and operated at global, regional, national or local levels, eliminate the requirement for constructing reference stations in distant locations far from the GNSS surveying areas (Eckl et al. 2001). Today, with the help of CORS networks that collect data 24 hours a day, we are able to produce new control points using the RP technique. However, to save the user from having to download reference stations from the CORS network, the International GNSS Service (IGS) and other organisations' open-access reference stations can be used (El-Mowafy 2011). Real-time applications, such as Real-Time Kinematic (RTK) positioning, require a CORS network. Many government agencies and private companies have established their own CORS networks to support RTK users (Rizos et al. 2012).

The RP approach is considered to be the most accurate and precise technique for positioning applications, especially geodetic, geodynamics and deformation research. Nevertheless, as the precise orbit and clock products have been launched by various organisations in the past few decades, PPP, which is an absolute positioning technique and a new technique for modelling diverse error sources, has been developed (Zumberge et al. 1997). It is an alternative technique, which ensures the acquisition of highly accurate spatial information from a single GNSS receiver (El-Mowafy 2009; Holden et al. 2017). Also, the PPP technique does not require data to be collected from CORS or IGS stations near prospective users (Guo 2015). Although PPP does not require any base or reference station, it does require accurate knowledge of precise orbit and clock products and Earth rotation parameters (ERPs) (Dow et al. 2009; Martín et. al 2011).

Using the PPP technique, observations produced by a single receiver determine not only its three coordinate components but also other parameters: for example, the receiver clock error and the total neutral atmosphere delay of the observations. PPP can be used mainly for positioning and a variety of other tasks, as the observation model must take into account the many effects inherent in GNSS signals and undifferenced observations, both ionospheric-free carrier-phase and code pseudorange. Because the observations from a single receiver are used, they are known as undifferenced (Leandro et al. 2011).

Whether through RP or PPP principle-based techniques, GNSS professionals process and analyse GNSS data using scientific or commercial software options of varying quality and cost. In addition to the expense, this software also requires users to be trained and experienced in using it. Therefore, as a solution to users with only a basic level of knowledge of GNSS post-processing, more user-friendly WB services were developed by several organisations to more easily evaluate the GNSS data (Ghoddousi-Fard and Dare 2006; Tsakiri 2008).

Bulletin of Geodetic Sciences, 26(1): e2020003, 2020 


\subsection{Web-based relative positioning and PPP post-processing services}

Several WB GNSS post-processing services have become available for less-skilled users from various organisations in recent years (Ghoddousi-Fard and Dare 2006; Tsakiri 2008). These organisations and their WB GNSS post-processing services for the RP approach are: Geoscience Australia's Online GPS Processing Service (AUSPOS; Geoscience Australia 2016), National Geodetic Survey (NGS)'s Online Positioning User Service (OPUS; NGS 2016), and Scripps Orbit and Permanent Array Center (SOPAC)'s the Scripps Coordinate Update Tool (SCOUT; SOPAC 2014).

WB RP post-processing services, through which data is collected in the "static" mode, primarily use the double-differenced phase measurements utilizing this equation (El-Mowafy 2011):

$$
\nabla \Delta \phi_{t}=\nabla \Delta r_{(t, t-\tau)}+\nabla \Delta d s_{(t-\tau)}-\nabla \Delta d_{\text {iono }}+\nabla \Delta d_{\text {tropo }}+\nabla \Delta d \lambda N+\nabla \Delta \varepsilon(\phi)
$$

where $\nabla \Delta$ is the double-difference operator at the time the receiver receives the data $(t)$ and $\phi$ signifies the phase measurement. $r_{(t, t-\tau)}$ is the true geometric range, where $(t-\tau)$ is the satellite time and refers to the travel time from the satellite to the receiver. $d s$ is the orbital prediction error and $d_{\text {iono }}$ and $d_{\text {tropo }}$ are the ionospheric and tropospheric errors, respectively. Finally, $\lambda$ is the wavelength, $N$ is the integer phase ambiguity and is the measurement noise (such as multipath, the user antenna centre variation and other effects).

The organisations for the PPP approach are National Resources Canada (NRCan)'s Canadian Spatial Reference System (CSRS-PPP; NRCan 2016), the University of New Brunswick's GPS Analysis and Positioning Service (GAPS; the University of New Brunswick 2016), GMV Aerospace and Defense company's Magic-PPP (MagicGNSS 2016), Jet Propulsion Laboratory (JPL)'s Automatic Precise Positioning Service (APPS; JPL 2014), and Trimble Navigation Limited's Trimble CenterPoint RTX Post-Processing (Trimble CenterPoint RTX PostProcessing Service 2014). Zumberge et al. (1997) and Kouba and Heroux (2001) stated that the ionospheric-free combinations of dual-frequency GPS pseudorange $(P)$ and carrier-phase observations $(\phi)$ in the PPP approach are related to the user position, satellite and receiver clock offset, and tropospheric and ambiguity parameters according to the following simplified observation equations:

$$
\begin{gathered}
P=\rho+C(d T-d t)+T_{r}+\varepsilon_{P} \\
\phi=\rho+C(d T-d t)+T_{r}+N \lambda+\varepsilon_{\phi}
\end{gathered}
$$

where $P$ is the ionosphere-free combination of $\mathrm{P} 1$ and $\mathrm{P} 2$ pseudoranges $(\mathrm{P} 3=2.546(\mathrm{P} 1)-1.546(\mathrm{P} 2))$ and $\phi$ signifies the ionosphere-free combination of L1 and L2 carrier phase observations $\left(L 3=2.546\left(\lambda_{1} \phi_{1}\right)-1.546\left(\lambda_{2} \phi_{2}\right)\right) . \rho$ is the geometrical range computed as a function of satellite and station coordinates, $C$ is the vacuum speed of light, $d T$ is the station receiver clock offset from the GPS time, $d t$ is the satellite clock offset from the GPS time, and $T_{r}$ is the signal path delay due to the neutral-atmosphere (primarily the troposphere). $N$ is the non-integer ambiguity of the carrier-phase ionosphere-free combination, and $\lambda_{1}, \lambda_{2}, \lambda$ are the carrier-phases $L 1, L 2$ and L3-combined $(10.7 \mathrm{~cm})$ wavelengths, respectively. Finally, $\varepsilon_{P}, \varepsilon_{\phi}$ are the relevant measurement noise components, including multipath, observable-dependent receiver bias, and observable-dependent satellite bias and other effects.

RP and PPP WB post-processing services use processing engines based on sophisticated scientific geodetic GNSS data processing software; they can be seen in the specifications and classifications in Table 1. Detailed information about the WB GNSS post-processing services can be found at the websites of the individual services; website links are provided in Table 1.

Users may submit data to the WB GNSS post-processing services' web pages or FTP sites via the internet. After the user submits the data to these services, they are then analysed, and the results returned include the estimated point coordinates and standard deviation (SD) values. Some of these services also send comprehensive analysis reports, which include a graphical illustration of these results. Although many of these services are open-access, some of them require a username and password for free access. However, in order to estimate high-accuracy coordinates for a point, some factors, 
Table 1: The specifications of web-based GNSS post-processing services

\begin{tabular}{|c|c|c|c|c|}
\hline Service & Technique & Organisations & Software & Website \\
\hline AUSPOS & \multirow{3}{*}{ RP } & Geoscience Australia & Bernese & http://www.ga.gov.au/bin/gps.pl \\
\hline OPUS & & National Geodetic Survey (NGS) & PAGES & https://www.ngs.noaa.gov/OPUS/ \\
\hline SCOUT & & SOPAC & GAMIT & http://sopac.ucsd.edu/cgi-bin/sCOUT.cgi \\
\hline CSRS-PPP & \multirow{5}{*}{ PPP } & National Resources Canada (NRCan) & NRCanPPP & $\begin{array}{l}\text { http://webapp.geod.nrcan.gc.ca/geod/ } \\
\text { tools- outils/ppp.php }\end{array}$ \\
\hline GAPS-PPP & & University of New Brunswick & GAPS & http://gaps.gge.unb.ca/ \\
\hline Magic-PPP & & $\begin{array}{l}\text { GMV Aerospace and Defense } \\
\text { company }\end{array}$ & MagicPPP & http://magicgnss.gmv.com/ppp \\
\hline APPS & & Jet Propulsion Laboratory (JPL) & Gipsy & http://apps.gdgps.net/ \\
\hline Trimble RTX & & Trimble Navigation Limited & Trimble & $\begin{array}{l}\text { https://www.trimble.com/positioning- } \\
\text { services/ }\end{array}$ \\
\hline
\end{tabular}

such as data processing solution techniques and algorithms (mathematical models) of the service used, the accuracy of the other data and products (e.g., reference station coordinates, satellite orbit and clock corrections), observation duration, and quality of the collected data, all play a significant role. While these services have several advantages for the less experienced users, they are also useful software for GNSS surveying and processing projects with concern about software, hardware, equipment, personnel and logistics costs. These WB services are routinely upgraded with new technological changes.

Both RP and PPP WB GNSS post-processing services use highly accurate and precise IGS data and products (e.g., Héroux et al. 2001). Encompassing more than 200 organisations from more than 100 countries, the IGS has more than twenty years of successful production and distribution of GNSS data. While the IGS makes important contributions to the development and enhancement of the GNSS standards around the world, it also has the vital function of collecting, archiving and presenting the high accuracy GPS/GLONASS ephemerides, satellite and orbit clocks, ERPs, coordinates and velocities of IGS tracking stations and atmospheric parameters (Dow et al. 2009; IGS 2017). Several additional organisations, including JPL, NRCan, the Center for Orbit Determination in Europe (CODE) and Bundesamt für Kartographie und Geodäsie (BKG), are significant data providers for GNSS positioning.

\section{Data and methodology}

\subsection{Field experiments}

This study tests the performances of RP and PPP techniques on three ground BMs with different satellite visibility conditions. 3 hours of static GNSS observations were carried out over 6 days, on 15th, 16th, 17th, 20th, 21st and 24th of May 2014 (GPS Day of the year (DoY): 135, 136, 137, 140, 141 and 144). Repeated measurements of the BMs will mask the effects of systematic errors, e.g., multipath will affect the Bernese GPS software and WB services solutions similarly, and centring errors over the BMs will vanish in the average values (Ebner and Featherstone 2008).

All multipath signals travel a longer path than the direct signal. A given point on the direct path signal will, therefore, arrive at the antenna earlier than the same point on any of the multipath signals (Braasch 2017). Multipath signals occur from the natural and human-made obstacles, which often cause signal reflection or diffraction. The impact of natural and human-made obstacles into the satellite signal is illustrated in Figure 1. Within this framework, the locations of the three BMs in Istanbul, Turkey were selected taking into consideration the impact of natural (e.g., trees) and human-made (e.g., buildings, roadside) obstacles, can be seen in Figure 2. 


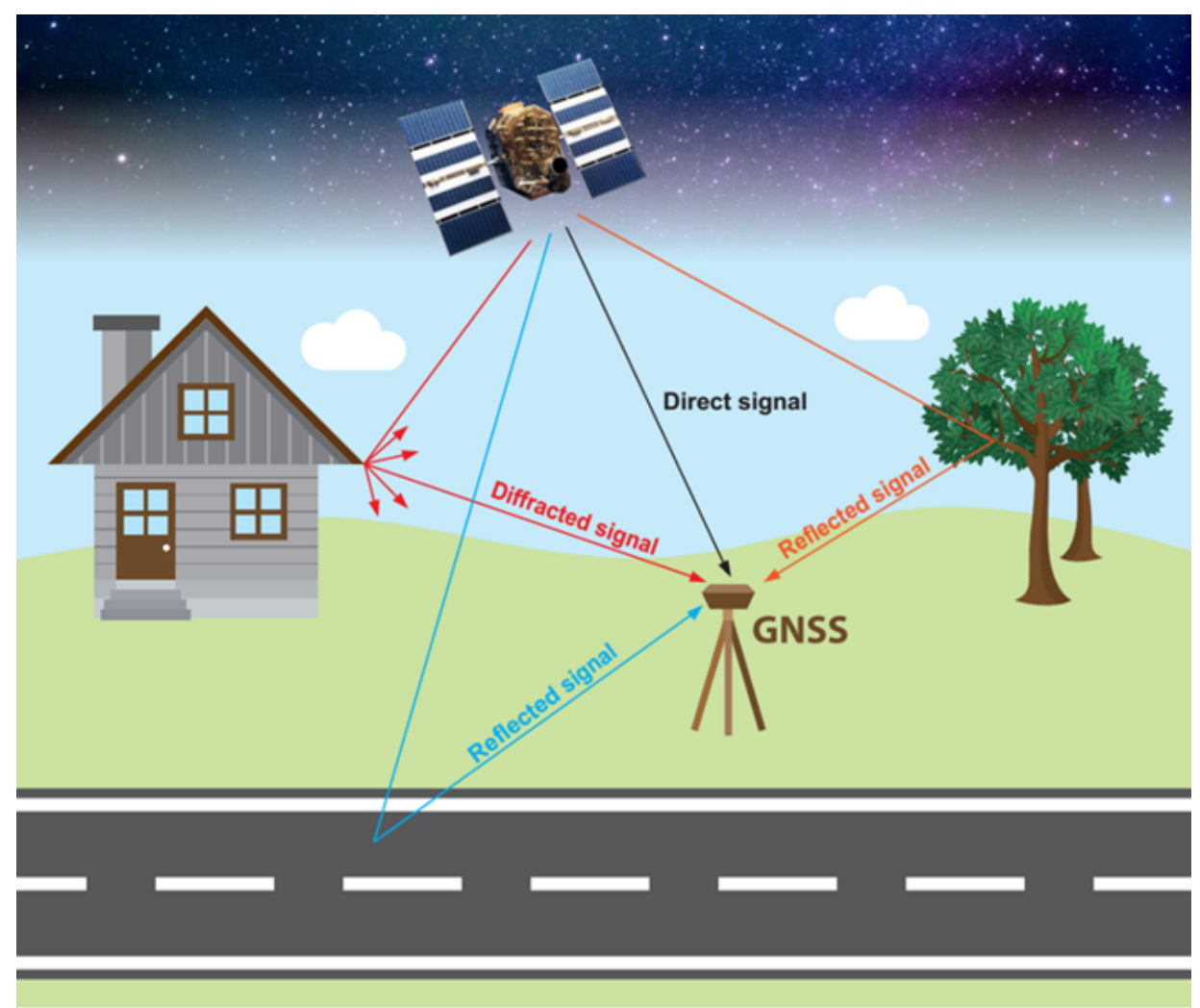

Figure 1: The impact of natural and human-made obstacles into the satellite signal. In addition to the desired direct path signal, there are three non-line of sight (LOS) signals impinging upon the antenna of the GNSS receiver. There are two reflected signals (one from the ground and one from the tree on the right) and one diffracted signal (from the building on the left).

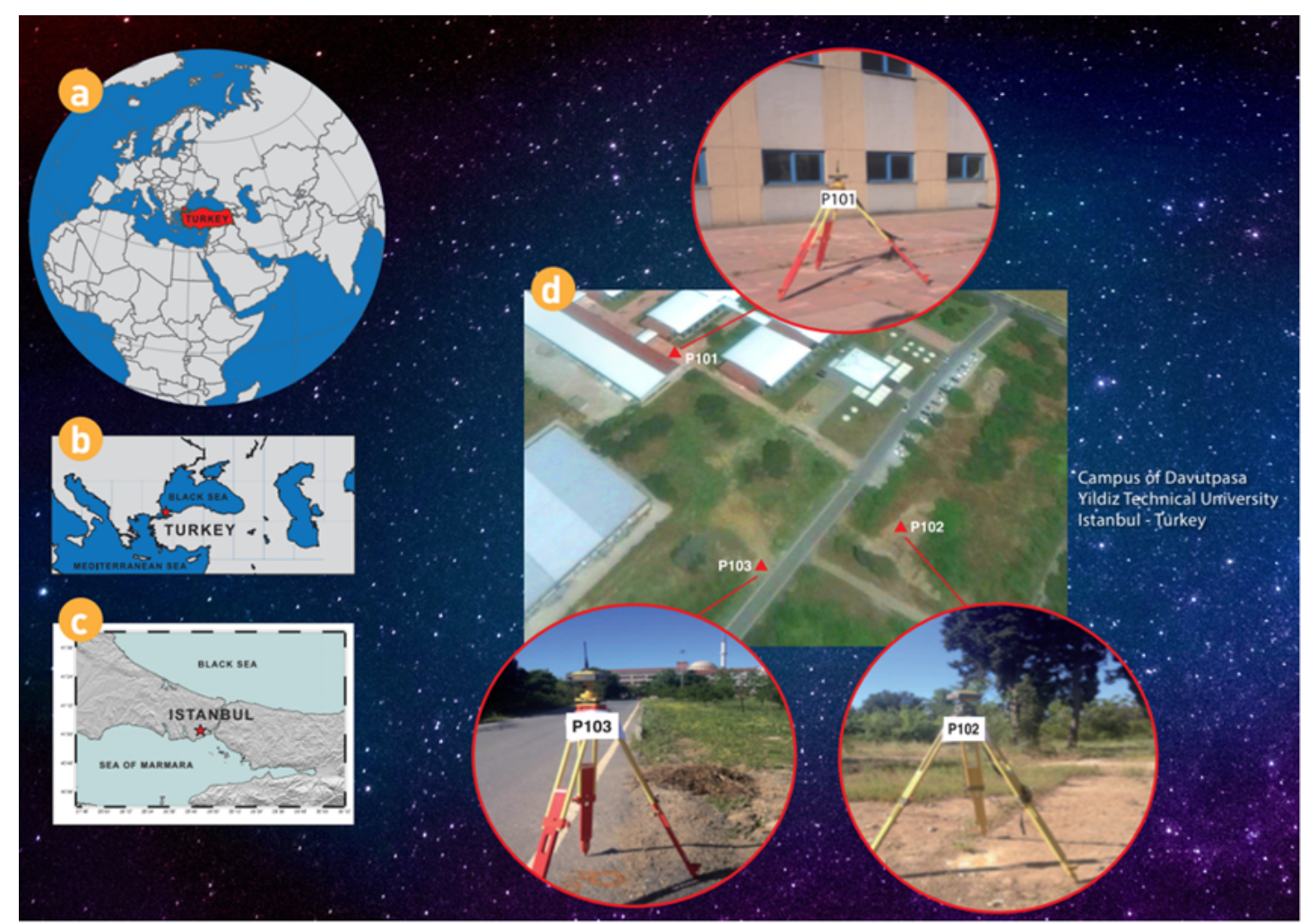

Figure 2: $(\mathbf{a}, \mathbf{b}, \mathbf{c})$ The study area was located on the Campus of Davutpasa, Yildiz Technical University in Istanbul, Turkey. (d) P101, P102 and P103 stations are located near buildings, a woodland area and the roadside, respectively. 
In Figure 2, the non-direct-path signals cause distortion, leading to code and phase measurement errors. Differential techniques do not completely eliminate this phenomenon, and therefore multipath errors remain an important source of error for researchers to be aware of when doing work that requires high precision and accuracy (Braasch 1996; Braasch 2017). Featherstone et al. (1998) emphasised that because multipath errors are site-dependent, it is almost impossible to quantify the exact size of these errors. Mitigation strategies to minimise multipath errors may be effectively implemented, but will not be considered in this study. Additional information about multipath mitigation can be found elsewhere (e.g., Ge et al. 2000; Braasch 2017).

\subsection{Features of the static GPS observation data}

In many studies, the baseline length, precision and measurement durations were investigated (Eckl et al. 2001; Snay et al. 2002; Psimoulis et al. 2004; Soler et al. 2006; Dogan 2007; Häkli et al. 2008; Weston et al. 2009; Aktug and Lenk 2010). The main reason the GNSS observations are conducted for at least 3 hours is that, in GNSS applications which contain measurements of more than three hours duration, the effect of baseline length on attitude becomes insignificant; a precision akin to that received for short baselines can also be obtained for long baselines. Above all, the fact that negative exponential distribution was obtained in baseline lengths for less than three hours of measurement duration, and the regression equations of measurement duration is taken as significant criteria in determining the utility of at least 3 hours of measurement duration (Aktug and Lenk 2010). Weston et al. (2009) analysed of the relationship between baseline length, precision and measurement duration for the measurement duration is up to $600 \mathrm{~km}$ baselines, and it was determined that precision change is not meaningful in over 3-hour measurements of these baselines. From this study, measurements carried out for more than 2 hours in the horizontal direction and more than 3 hours in vertical directions do not cause significant changes. Geng et al. (2010) also emphasised that 3 hours of observations for static PPP should be used if a reliable millimetre positioning accuracy is required.

Taking the findings of former studies about baseline length, measurement duration, and accuracy of point position into consideration, at least 3-hour long GNSS observation at each BM during the six days were attempted. The simultaneous static GNSS observations are independent of each other and are presented in Table 2. From this table, the measurements were done in at least 3-hour session at each BM with the exception of P102 in the GPS DoY 140 , which ended earlier than expected due to the technical malfunctions.

In this study, only the GPS observations were used in the analysis. In the field measurements, the data record interval was set at 1 second, and the satellite elevation cut-off angle was set of $10^{\circ}$. The Topcon HyperPRO GNSS receivers were used in the acquisition of static GPS observations. The raw data collected in the field was converted into receiver independent exchange (RINEX) format, resulting in eighteen RINEX files acquired for six observation days at three BMs.

Table 2: The static GNSS observations durations

\begin{tabular}{cccc}
\hline GPS DoY & P101 & P102 & P103 \\
\hline 135 & $07: 09-10: 12$ & $07: 16-10: 22$ & $06: 58-10: 23$ \\
\hline 136 & $07: 50-10: 54$ & $07: 50-10: 57$ & $07: 50-10: 56$ \\
\hline 137 & $06: 08-09: 17$ & $06: 20-09: 20$ & $06: 16-09: 19$ \\
\hline 140 & $07: 07-10: 30$ & $07: 20-09: 08$ & $07: 16-10: 32$ \\
\hline 141 & $05: 34-08: 44$ & $05: 44-08: 48$ & $05: 42-08: 46$ \\
\hline 144 & $10: 53-13: 58$ & $10: 57-14: 00$ & $10: 55-14: 00$ \\
\hline
\end{tabular}




\section{Results}

\subsection{The GPS data processing through Bernese GPS software version 5.0}

The scientific software packages Bernese (Dach et al. 2007 and 2015), GIPSY/OASIS II (Lichten et al. 1995; Webb and Zumberge 1997) and GAMIT (King and Bock 2005) are frequently used to obtain highly accurate coordinates for GNSS data processing. Because of its availability, the Bernese GPS software v5.0 (Dach et al. 2007) was chosen to process GPS observations for this study. The 6-day average for the local coordinates from the three control BMs (P101, P102 and P103), calculated using the Bernese software RP approach based on IGS stations, were accepted as true (reference) results. The two IGS stations chosen to process GPS observations, ISTA (Istanbul, Turkey) and TUBI (Gebze, Turkey), were selected for their location and accessibility. The final GPS satellite ephemerides and earth rotation parameters obtained from precise IGS products were used in the Bernese GPS software v5.0 analysis.

In the first processing step, single point positioning is performed by using ionosphere-free (L3) observations, receiver clock errors are eliminated, and coordinates of the reference stations in the network are pre-determined. Cycle slips and outliers have been controlled by using triple differences. After this process, the outliers are removed. If the carrier phase cycle slips are the problem, then they are fixed. Ambiguity parameters will be computed. Then, the ambiguity parameters are resolved. In order to resolve these ambiguity parameters, the Quasi lonosphere Free (QIF) strategy has been applied. The Saastamoinen model (Saastamoinen 1972) was chosen for the tropospheric delays at each station, and these delays have been eliminated by determining the zenith delay parameters computed in constant time intervals. Consequently, Cartesian coordinates $(X, Y, Z)$ of the three BMs in ITRF2008 reference frame were computed. The Cartesian coordinates were transformed into local coordinates (North [N], East [E], $\mathrm{Up}[\mathrm{U}])$ and assigned as true coordinates to be compared with RP and PPP WB GNSS services' coordinates. These Bernese-derived averaged coordinates and their SDs in the local coordinate system in the ITRF2008 reference frame are presented in Table 3.

\subsection{The data process through web-based post-processing services}

In this study, five out of eight available WB GNSS post-processing services were used. SCOUT and APPS, which are the RP and PPP WB GNSS post-processing services, respectively, were not usable due to upload restrictions for RINEX files. While SCOUT has a $10 \mathrm{MB}$ RINEX-file restriction, APPS has a member restriction of $10 \mathrm{MB}$ and a nonmember restriction of $5 \mathrm{MB}$. The datasets, we obtained from fieldwork are approximately $20 \mathrm{MB}$ per file, which rendered these services unusable in this study. Also, the Trimble RTX was not used in this study because it does not support our GNSS antenna type (Albayrak 2014; Albayrak et al. 2016).

To use the RP post-processing WB services, users submit information through the web interface, including

Table 3: The results of the Bernese-derived averaged coordinates and their standard deviations (SDs) in the local coordinate system [N: North, E: East, U: Up] in the ITRF2008 reference frame

\begin{tabular}{ccccccc}
\hline Benchmarks & $\mathrm{N}(\mathrm{m})$ & $\mathrm{E}(\mathrm{m})$ & $\mathrm{U}(\mathrm{m})$ & $\mathrm{SD}_{\mathrm{N}}(\mathrm{cm})$ & $\mathrm{SD}_{\mathrm{E}}(\mathrm{cm})$ & $\mathrm{SD}_{U}(\mathrm{~cm})$ \\
\hline $\mathrm{P} 101$ & 2551.329 & 4587.605 & 1.289 & 0.531 & 0.380 & 0.624 \\
\hline P102 & 2466.929 & 4674.271 & 0.382 & 0.244 & 0.150 & 0.223 \\
\hline P103 & 2452.139 & 4630.607 & 1.109 & 0.208 & 0.139 & 0.202 \\
\hline
\end{tabular}


their e-mail addresses, the GPS receiver antenna type used and the antenna height from the antenna reference point (ARP). For the PPP WB services, in contrast, this information is obtained from the RINEX-files directly. In addition to this information, users can specify other variables, such as ocean tidal loading corrections files. The user can also change the elevation cut-off angle, which defaults to $10^{\circ}$ in GAPS and Magic-PPP services. In summary, there are three steps for using WB PPP services: upload the RINEX-file, select static or kinematic mode and provide their e-mail address.

The final reports sent to the user contain calculated point coordinates and SD values. Additionally, some services present comprehensive analysis reports with a graphical illustration. The processing speed of WB GNSS post-processing services at the same internet speed are approximately $6 \mathrm{~min}$. for AUSPOS, $3 \mathrm{~min}$. for OPUS, $4 \mathrm{~min}$. for CSRS-PPP, 1 min. for Magic-PPP and 50 seconds for GAPS. Four services share the processing speed in their final report; only GAPS does not share this information.

All eighteen RINEX files were evaluated by the five services, producing ninety result files. All services except for Magic-PPP sent the final reports via e-mail. The Magic-PPP service differs from other services because of its WB GNSS data evaluation, which enables the user to reach the result files through the data upload page.

The averages of the local coordinates over the six days, processed through the Bernese GPS software v5.0 for P101, P102, and P103, were selected as the reference coordinates. The average Bernese coordinates and the 6-day WB services coordinates, in the local coordinate system, for P101, P102 and P103 BMs are plotted by their horizontal (N, E) and vertical (U) components, which can be found in Figure A1 in the Appendix.

\subsection{Comparison of Bernese GPS software and web-based GNSS post-processing services}

The coordinate results are analysed in-depth through coordinate differences $(\Delta N, \Delta E, \Delta U)$. The coordinate differences are the Bernese solution minus the WB services solution. The graphics displaying the coordinate differences of the six days (GPS DoY: $135,136,137,140,141$ and 144) that belong to $\Delta N, \Delta E$ and $\Delta U$ components of P101, P102 and P103 can be found respectively in Figures 3, 4 and 5. In these Figures, the accuracy of the horizontal component differences ( $\Delta N$ and $\Delta E$ ) are at the cm-level (except $\Delta E$ of P101 for Magic-PPP [GPS DoY 137 and 138] and AUSPOS [GPS DoY 144]). However, vertical component differences $(\Delta U)$ for P101 and P102 BMs for WB PPP services are generally at dm-level accuracy.

\subsection{Analysis of the Results}

The descriptive statistical summary of the coordinate differences $(\Delta)$ obtained from the selected BMs is presented in Table 4. In this table, the vertical component differences $(\Delta U)$ are at the $\mathrm{dm}$ level and thus have low accuracy when compared with the horizontal component differences. $\Delta \mathrm{N}$ provides the best SD results, and $\Delta E$ also has good SD results for the three BMs. We also see that the SDs of the horizontal components of P102 and P103 BMs are not very different from each other, and provide a better result than P101. Receivers at P101 are subjected to intense satellite signal visibility obstacles; therefore, the accuracy of the results obtained through WB services is relatively lower compared to $\mathrm{P} 102$ and P103, which are only partially exposed to satellite signal visibility obstacles.

The SDs of the $\Delta N, \Delta E$ and $\Delta U$ components for P101, P102 and P103 BMs' WB services are presented in Table 5 and Figure 6 . In this Table and Figure, we can see that the best SDs for the WB services is given by OPUS in the $\triangle E$ and $\triangle U$ components and by GAPS in the $\triangle N$ component of P101; by AUSPOS in the $\triangle E$ component, by OPUS in the $\Delta \mathrm{N}$ component and by CSRS-PPP in the $\triangle \mathrm{U}$ component of P102; and, by AUSPOS in the $\triangle \mathrm{N}$ and $\triangle \mathrm{E}$ components and 

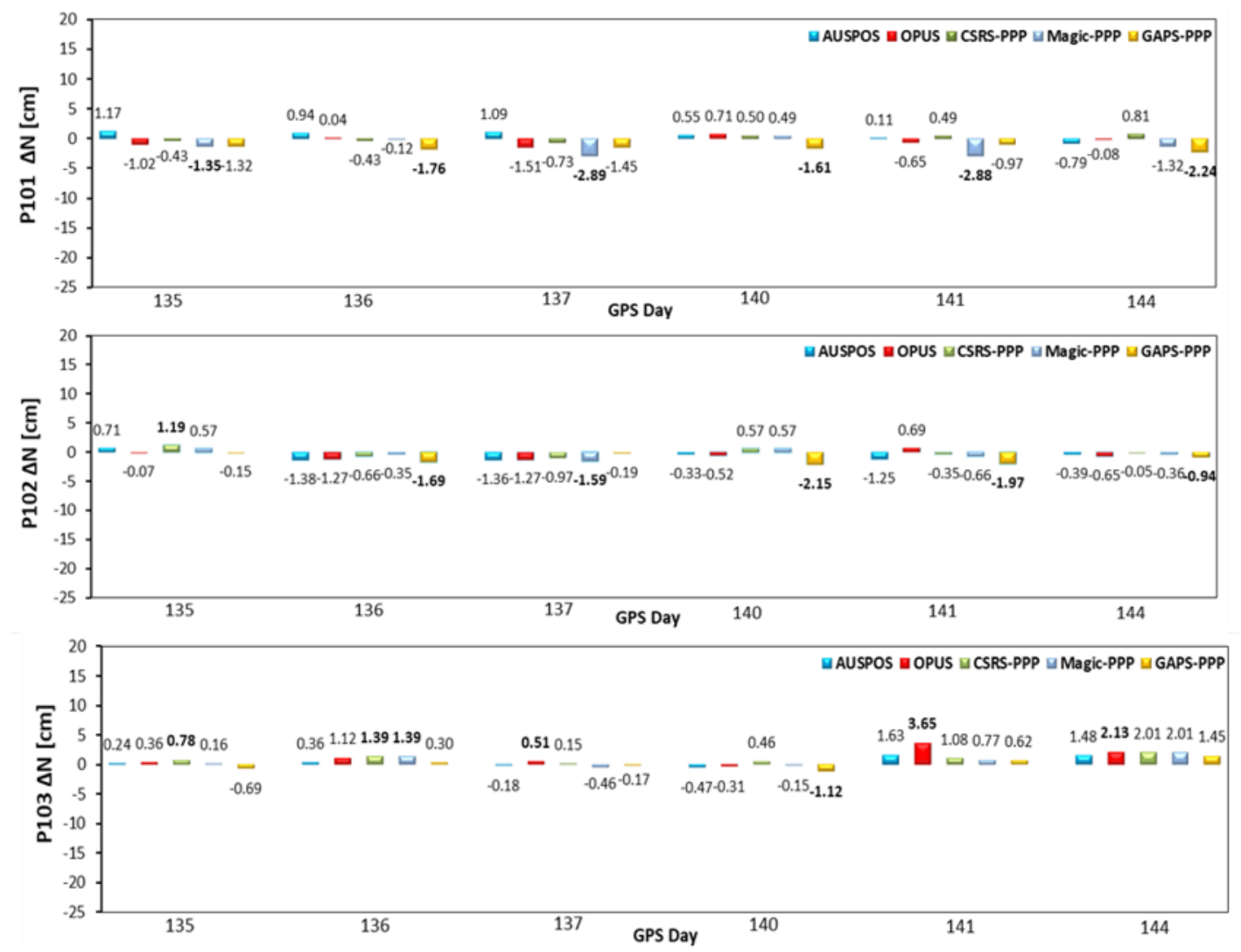

Figure 3: Coordinate differences of North $(\Delta N)$ component between the Bernese software v5.0 and web-based services over 6 days for P101, P102 and P103
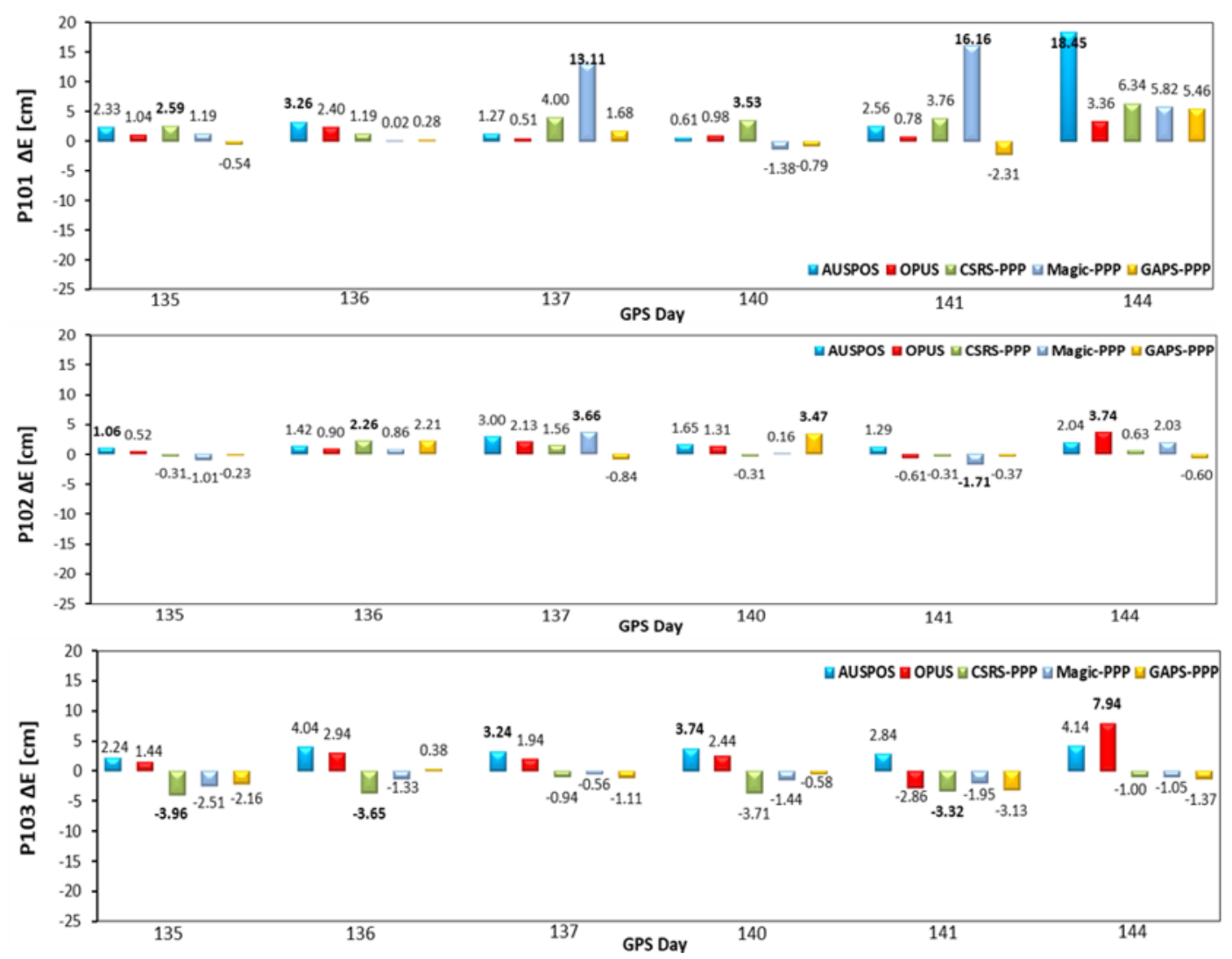

Figure 4: Coordinate differences of East $(\triangle E)$ component between the Bernese software and web-based services over 6 days for $\mathrm{P} 101, \mathrm{P} 102$ and $\mathrm{P} 103$ 

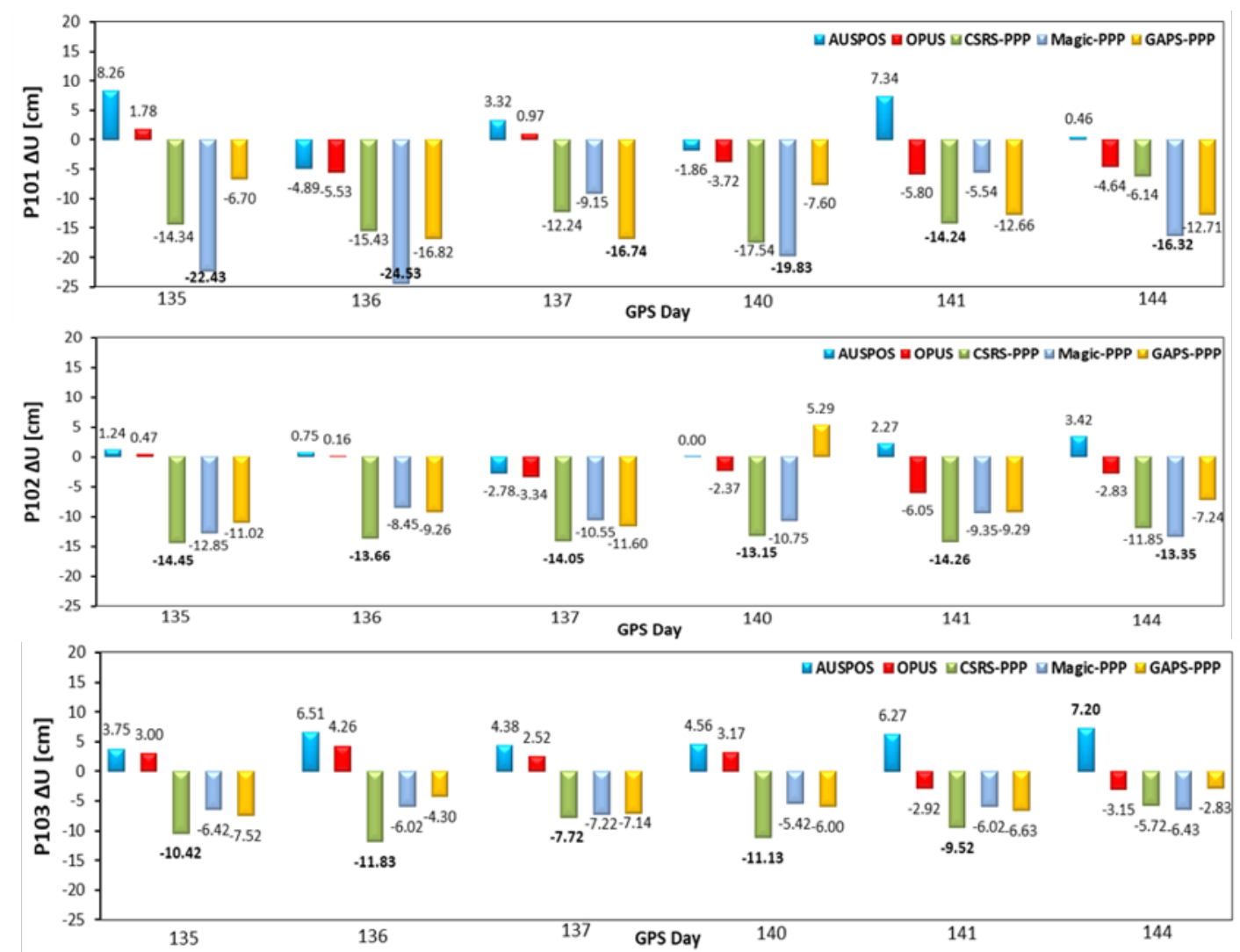

Figure 5: Coordinate differences of $U p(\Delta U)$ component between the Bernese software and web-based services over 6 days for P101, P102 and P103

Table 4: Descriptive statistical summary of the coordinate differences $(\Delta)$ obtained with web-based GNSS Services and Bernese software v5.0 [in units of $\mathrm{cm}$ ]

\begin{tabular}{cccccccccc}
\hline & \multicolumn{3}{c}{$\mathrm{P} 101$} & \multicolumn{3}{c}{$\mathrm{P} 102$} & \multicolumn{3}{c}{$\mathrm{P} 103$} \\
\hline & $\Delta \mathrm{N}$ & $\Delta \mathrm{E}$ & $\Delta \mathrm{U}$ & $\Delta \mathrm{N}$ & $\Delta \mathrm{E}$ & $\Delta \mathrm{U}$ & $\Delta \mathrm{N}$ & $\Delta \mathrm{E}$ & $\Delta \mathrm{U}$ \\
\hline Min & -2.89 & -2.31 & -24.53 & -2.15 & -1.71 & -14.45 & -1.12 & -0.73 & -11.83 \\
\hline Max & 1.17 & 18.45 & 8.26 & 1.19 & 3.74 & 5.29 & 3.65 & 11.14 & 7.20 \\
\hline Mean & -0.56 & 3.26 & -8.51 & -0.54 & 0.99 & -6.63 & 0.68 & 1.50 & -2.96 \\
\hline SD & 1.14 & 4.80 & 8.51 & 0.85 & 1.46 & 6.20 & 1.02 & 2.03 & 5.85 \\
\hline
\end{tabular}

Table 5: The SDs of the $\Delta N, \Delta E$ and $\Delta U$ components of P101, P102 and P103 BMs [in units of cm]

\begin{tabular}{cccccccccc}
\hline & \multicolumn{3}{c}{$\mathrm{P} 101$} & \multicolumn{3}{c}{$\mathrm{P} 102$} & \multicolumn{3}{c}{$\mathrm{P} 103$} \\
\hline WB Services & $\Delta \mathrm{N}$ & $\Delta \mathrm{E}$ & $\Delta \mathrm{U}$ & $\Delta \mathrm{N}$ & $\Delta \mathrm{E}$ & $\Delta \mathrm{U}$ & $\Delta \mathrm{N}$ & $\Delta \mathrm{E}$ & $\Delta \mathrm{U}$ \\
\hline AUSPOS & 0.75 & 6.78 & 5.18 & 0.83 & 0.70 & 2.13 & 0.86 & 0.51 & 1.39 \\
\hline OPUS & 0.80 & 1.12 & 3.34 & 0.75 & 1.48 & 2.41 & 1.44 & 4.29 & 3.29 \\
\hline CSRS-PPP & 0.64 & 1.70 & 3.92 & 0.81 & 1.11 & 0.96 & 0.67 & 0.84 & 2.29 \\
\hline Magic-PPP & 1.39 & 7.31 & 7.55 & 0.81 & 1.98 & 1.92 & 0.95 & 0.96 & 0.60 \\
\hline GAPS & 0.43 & 2.70 & 4.33 & 0.89 & 1.79 & 6.30 & 0.93 & 1.09 & 1.82 \\
\hline
\end{tabular}




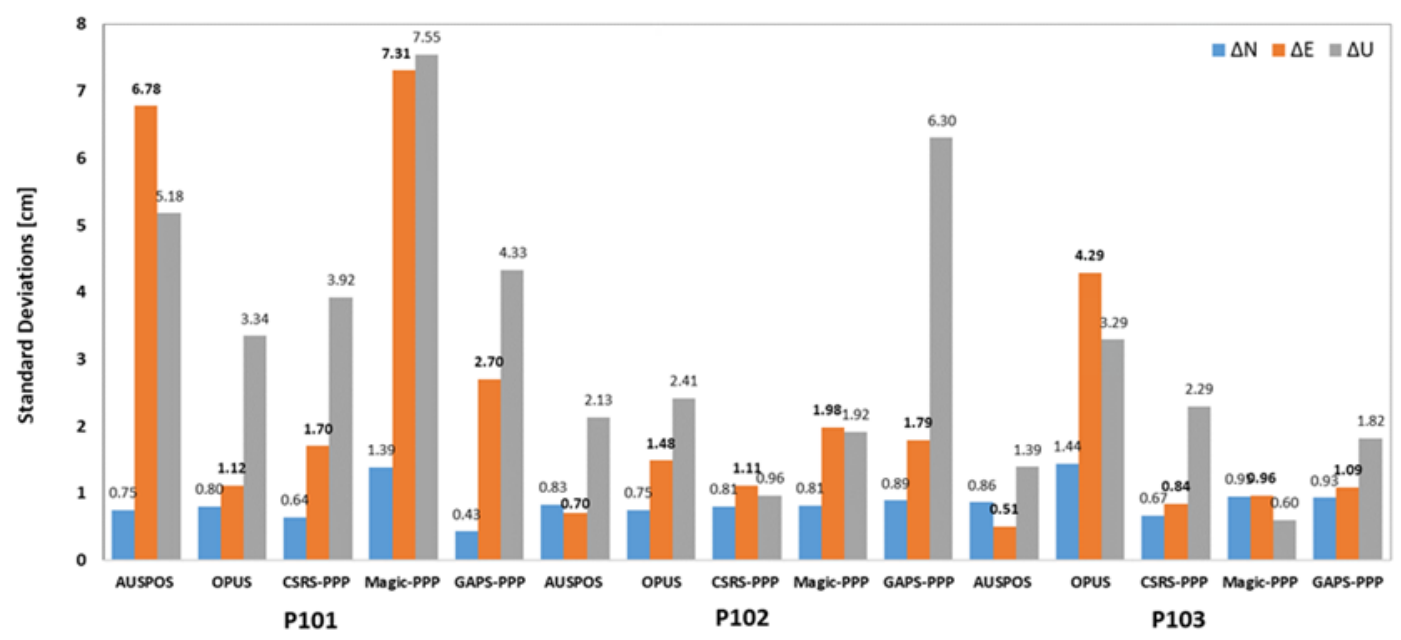

Figure 6: The standard deviations of the $\Delta N, \Delta E$ and $\Delta U$ components for P101, P102 and P103 Benchmarks' webbased services

by Magic-PPP in the $\triangle \mathrm{U}$ component of P103. As emphasised earlier, the fact that the AUSPOS and OPUS services give the closest results to the reference coordinates calculated through the Bernese software is an indication that the RP principle is still dominant for acquiring high accuracy and high precise point positioning data. Looking at the SDs are given in Table 5 and Figure 6 for the three services that use the PPP technique, we see that the best results have been produced by: GAPS in the $\Delta \mathrm{N}$ component, and CSRS-PPP in the $\triangle E$ and $\triangle \mathrm{U}$ components of P101; CSRS-PPP in the $\triangle E$ and $\triangle \mathrm{U}$ components and CSRS-PPP and Magic-PPP provide the same SDs result in the $\Delta \mathrm{N}$ component of P102; CSRS-PPP in the $\Delta N$ and $\Delta E$ components, and Magic-PPP in the $\Delta U$ component of P103.

\section{Conclusions}

Measurements were taken in one geographic area-Istanbul, Turkey-which has many potential error sources. These measurements allowed us to evaluate the RP and PPP techniques based on WB GNSS post-processing services as alternatives to GNSS scientific and commercial data evaluation software. Scientific and commercial RP and PPP techniques require user experience and an expensive license fee. However, open-access RP and PPP WB GNSS processing services have been developed for less-skilled users by various institutions (see Section 2.1). Basic GNSS positioning and data evaluation application users can also benefit from these services which provide easy and effective solutions for geodetic positioning applications.

We see that the results, acquired from the evaluation of 3-hour static observations at three control BMs with different visibility conditions, indicate that WB RP and PPP services' results are closer to the results acquired through the Bernese v5.0 software (see Section 4). These results show that the current WB services are reliable, especially in regard to measurements at the $\mathrm{cm}$-level geodetic applications.

The services which give the best results are AUSPOS and OPUS, which use the RP technique. Considering the measurement duration criteria for obtaining high accuracy and high precision point position information, the RP technique is still predominant compared to the PPP principle.

In the comparison of the horizontal (N, E) and vertical (U) coordinate differences between the Bernese and the WB GNSS post-processing software, we see that the horizontal coordinates' results from both software packages are better than vertical coordinates' results for three BMs. 
Taking the ground control BM selection criteria into consideration, the P101 BM was located near buildings and thus were subjected to intense satellite visibility obstacles. These, as expected, gave results farthest from the reference coordinates. On the other hand, the P102 BM was located in woodland and was presumably subjected to satellite visibility obstacles, while the P103 BM was along the roadside and also had slight satellite visibility obstacles which converged to the reference coordinates in approximately the same proportion. However, the P103 BM was closer to reference coordinates estimated by Bernese v5.0.

In light of these findings and the principles of the Regulations for Large Scale Mapping and Map Information Production, which form a legal basis for the production of large-scale maps with geodetic and photogrammetric techniques in Turkey, it is possible to use RP and PPP WB services in the production of 3rd order $-\mathrm{C}(\mathrm{C} 1, \mathrm{C2}, \mathrm{C}$, C4) degree-ground control BMs in the data post-processing stage (BOHHBUY 2005). Position accuracy, provided by RP services, fulfils the accuracy criteria stipulated in these Regulations. Also, the PPP technique continues to develop and is commonly used in many applications due to its accuracy. Therefore, it is projected that PPP and WB services based on the PPP technique will be more effective in the future. Various software developed as a basis for international projects are used by IGS for the real-time application of the PPP technique, as supported by postprocessing data evaluation.

\section{ACKNOWLEDGEMENT}

The first author is grateful to the Fulbright Foundation and to Prof. CK Shum for their support during the data analysis and writing process for this manuscript. The authors want to thank the IGS for the data products, and the GNSS post-processing web-based online service developers and data providers used in this study (AUSPOS, OPUS, CSRS-PPP, Magic-PPP, GAPS). We are grateful to the Geomatics Engineering Department at Yildiz Technical University for supporting the field measurements. We also thank the anonymous reviewers for their valuable comments on the manuscript and the Editor for the handling of the review process. Figure 2 (c) was drawn using the Generic Mapping Tools (GMT) from Wessel et al. (2013).

\section{AUTHOR'S CONTRIBUTION}

Müge Albayrak: contributed to all phases of data acquisition, to the creation of figures and plots, and to the writing of the manuscript. Bahattin Erdoğan: contributed to all phases of data acquisition and to the writing of the manuscript. Halil Erkaya: conceived of and designed the structure of the research and analysis.

\section{References}

Aktug B, Lenk O (2010) Yeni gelişmeler ışığında ağ hiyerarşisi, ölçü süreleri ve duyarlık ölçütlerinin incelenmesi (An overview of network hierarchy, observation time spans and precision criteria of in view of the recent developments). Harita Dergisi (144):40-50 [In Turkish].

Albayrak M (2014) Web tabanlı bağıl ve mutlak konum belirleme servislerinin performans analizi (Performance analysis of web-based relative and absolute positioning services), Master Thesis, Graduate School of Natural and Applied Sciences, Yildiz Technical University, Istanbul, Turkey [In Turkish].

Albayrak M, Erkaya H, Ozludemir MT, Ocalan T (2016) Performance analysis of web-based PPP services with different 
visibility conditions. In 2016 AGU Fall Meeting, December 12-16, San Francisco, CA. Abstract (G31B-1056). http:// adsabs.harvard.edu/abs/2016AGUFM.G31B1056A

BOHHBUY (2005) Büyük Ölçekli Harita ve Harita Bilgileri Üretim Yönetmeliği (Regulations for Large Scale Mapping and Map Information Production (RLSMMI)) [In Turkish].

Braasch MS (1996) GPS multipath model validation. Proceedings of Position, Location and Navigation SymposiumPLANS'96. pp. 672-8. https://doi.org/10.1109/PLANS.1996.509144

Braasch MS (2017) Multipath. In Springer Handbook of Global Navigation Satellite Systems. pp. 443-68. https://doi. org/10.1007/978-3-319-42928-1_15

Dach R, Hugentobler U, Fridez P, Meindl M (2007) Bernese GPS software version 5.0. Astronomical Institute, University of Bern, Switzerland.

Dach R, Lutz S, Walser P, Fridez P (Eds) (2015) Bernese GNSS software version 5.2. User manual, Astronomical Institute, University of Bern, Switzerland. Bern Open Publishing. https://doi.org/10.7892/boris.72297; ISBN: 978-3906813-05-9.

Dogan U (2007) Accuracy analysis of relative positions of permanent GPS stations in the Marmara region, Turkey. Survey Review 39 (304): 156-165. https://doi.org/10.1179/003962607X165113

Dow JM, Neilan RE, Rizos C (2009) The International GNSS Service in a changing landscape of Global Navigation Satellite Systems. Journal of Geodesy 83(3-4):191-8. https://doi.org/10.1007/s00190-008-0300-3

Ebner R, Featherstone WE (2008) How well can online GPS PPP post-processing services be used to establish geodetic survey control networks?. Journal of Applied Geodesy 2(3):149-57. https://doi.org/10.1515/JAG.2008.017

Eckl MC, Snay RA, Soler T, Cline MW, Mader GL (2001) Accuracy of GPS-derived relative positions as a function of interstation distance and observing-session duration. Journal of Geodesy 75(12):633-40. https://doi.org/10.1007/ s001900100204

El-Mowafy A (2009) Alternative postprocessing relative positioning approach based on precise point positioning. Journal of Surveying Engineering 135(2):56-65. https://doi.org/10.1061/(ASCE)0733-9453(2009)135:2(56)

El-Mowafy A (2011) Analysis of web-based GNSS post-processing services for static and kinematic positioning using short data spans. Survey Review 43(323):535-49. https://doi.org/10.1179/003962611X13117748892074

Featherstone WE, Dentith MC, Kirby JF (1998) Strategies for the accurate determination of orthometric heights from GPS. Survey Review 34(267):278-96. https://doi.org/10.1179/sre.1998.34.267.278

Gao Y, Chen K (2004) Performance analysis of precise point positioning using real-time orbit and clock products. Journal of Global Positioning Systems 3(1-2):95-100.

GAPS (2016) GPS analysis and positioning software (GAPS) home page. http://gaps.gge.unb.ca, (June 2016).

Ge L, Han S, Rizos C (2000) Multipath mitigation of continuous GPS measurements using an adaptive filter. GPS Solutions 4(2):19-30. https://doi.org/10.1007/PL00012838

Geng J, Meng X, Teferle FN, Dodson AH (2010) Performance of precise point positioning with ambiguity resolution for 1-to 4-hour observation periods. Survey Review 42(316): 155-65. https://doi.org/10.1179/00396261 0X12572516251682

Geoscience Australia (2016) AUSPOS online GPS processing service home page. http://www.ga.gov.au/scientifictopics/positioning-navigation/geodesy/auspos/ (June 2016).

Ghoddousi-Fard R, Dare P (2006) Online GPS processing services: an initial study. GPS Solutions 10(1): 12-20. https:// doi.org/10.1007/s10291-005-0147-5

Guo Q (2015) Precision comparison and analysis of four online free PPP services in static positioning and tropospheric delay estimation. GPS Solutions 19(4): 537-44. https://doi.org/10.1007/s10291-014-0413-5

Häkli P, Koivula H, Puupponen J (2008) Assessment of Practical 3-D Geodetic Accuracy for Static GPS Surveying, 
Integrating Generations. In FIG Working Week, June 14-19, Stockholm, Sweden.

Héroux P, Kouba J (2001) GPS precise point positioning using IGS orbit products. Physics and Chemistry of the Earth, Part A: Solid Earth and Geodesy 26(6-8): 573-8. https://doi.org/10.1016/S1464-1895(01)00103-X

Héroux P, Kouba J, Collins P, Lahaye F (2001) GPS carrier-phase point positioning with precise orbit products. In the KIS 2001, June 5-8, Banff, Alberta, Canada.

Hirt C, Schmitz M, Feldmann-Westendorff U, Wübbena G, Jahn CH, Seeber G (2010) Mutual validation of GNSS height measurements and high-precision geometric-astronomical levelling. GPS Solutions 15(2): 149-159. https:// doi.org/10.1007/s10291-010-0179-3

Hofmann-Wellenhof B, Lichtenegger H, Wasle E (2007) GNSS - global navigation satellite systems: GPS, GLONASS, Galileo, and more. Springer Science \& Business Media.

Holden L, Silcock D, Choy S, Cas R, Ailleres L, Fournier N (2017) Evaluating a campaign GNSS velocity field derived from an online precise point positioning service. Geophysical Journal International 208(1):246-56. https://doi. org/10.1093/gji/ggw372

IGS (2017) The International GNSS Service (IGS) home page. http://igs.org, (December 2017).

Jet Propulsion Laboratory (2014) The Jet Propulsion Laboratory (JPL) APPS Service home page. http://apps.gdgps. net, (November 2014).

King RW, Bock Y (2005) Documentation for the GAMIT GPS processing software release 10.2, Massachusetts Inst. of Technology., Cambridge, MA

Langley RB, Teunissen PJ, Montenbruck O (2017) Introduction to GNSS. In Springer Handbook of Global Navigation Satellite Systems, pp. 3-23. https://doi.org/10.1007/978-3-319-42928-1_1

Leandro RF, Santos MC, Langley RB (2011) Analyzing GNSS data in precise point positioning software. GPS Solutions 15(1):1-13. https://doi.org/10.1007/s10291-010-0173-9

Lichten SM, Bar-Sever YE, Bertiger EI, Heflin M, Hurst K, Muellerschoen RJ, Wu SC, Yunck TP, Zumberge JF (1995) GIPSY/OASIS II: A High precision GPS Data processing System and general satellite orbit. Tech. Rep. 95-1323, Jet Propul. Lab., Calif. Inst. of Technol., Pasadena, Calif.

MagicGNSS (2016) MagicGNSS home page. http://magicgnss.gmv.com, (June 2016).

Martín A, Anquela AB, Capilla R, Berné JL (2011) PPP technique analysis based on time convergence, repeatability, IGS products, different software processing, and GPS+GLONASS constellation. Journal of Surveying Engineering 137(3):99-108. https://doi.org/10.1061/(ASCE)SU.1943-5428.0000047

National Geodetic Survey (2016) National Geodetic Survey, Online positioning user service (OPUS) home page. http://www.ngs.noaa.gov/OPUS/, (June 2016).

Natural Resources Canada (2016) Natural Resources Canada, precise point positioning home page. http://webapp. geod.nrcan.gc.ca/geod/tools-outils/ppp.php?locale=en, (June 2016).

Psimoulis PA, Kontogianni VA, Nickitopoulou A, Pytharouli SI, Triantafyllidis P, Stiros SC (2004) Estimating the optimum duration of GPS static observations for short baseline length determination in Greece. In FIG Working Week, May 22-24, Athens, Greece.

Rizos C, Janssen V, Roberts C, Grinter T (2012) Precise point positioning: Is the era of differential GNSS positioning drawing to an end? In FIG Working Week, May 6-10, Rome, Italy. https://eprints.utas.edu.au/13280/

Rizos C (2017) Surveying. In Springer Handbook of Global Navigation Satellite Systems, pp. 1011-37. https://doi. org/10.1007/978-3-319-42928-1_35

Saastamoinen J (1972) Atmospheric correction for the troposphere and stratosphere in radio ranging satellites. The Use of Artificial Satellites for Geodesy 15:247-51.

Snay RA, Soler T, EckI M (2002) GPS precision with carrier phase observations: Does distance and/or time matter?. 
Professional Surveyor 22(10):20-2

Soler T, Michalak P, Weston ND, Snay RA, Foote RH (2006) Accuracy of OPUS solutions for 1-to 4-h observing sessions. GPS Solutions 10(1):45-55. https://doi.org/10.1007/s10291-005-0007-3

SOPAC (2014) Scripps orbit and permanent array center home page. http://sopac-csrc.ucsd.edu, (November 2014).

Trimble Centerpoint RTX Post-processing Service (2014) Trimble centerpoint RTX post-processing service home page. http://www.trimblertx.com/UploadForm.aspx, (November 2014).

Tsakiri M (2008) GPS processing using online services. Journal of Surveying Engineering 134(4):115-25. https://doi. org/10.1061/(ASCE)0733-9453(2008)134:4(115)

Webb FH, Zumberge JF (1997) An Introduction to GIPSY/OASIS-II. JPL Publication D-11088.

Wessel P, Smith WHF, Scharroo R, Luis J, Wobbe F (2013) Generic mapping tools: improved version released. Eos, Transactions American Geophysical Union 94(45): 409-410. https://doi.org/10.1002/2013EO450001

Weston ND, Soler T, Mader GL (2009) Rover station positional accuracies from OPUS as a function of reference station spacing and rover station occupation time. In FIG Working Week, May 3-11, Eilat, Israel.

Wübbena G, Schmitz M, Menge F, Böder V, Seeber G (2000) Automated absolute field calibration of GPS antennas in real-time. In ION GPS-00, September 19-22, Salt Lake City, Utah, USA.

Wübbena G, Schmitz M, Boettcher G (2006) Near-field effects on GNSS sites: Analysis using absolute robot calibrations and procedures to determine corrections. In IGS Workshop 2006 Perspectives and Visions for 2010 and beyond, May 8-12, ESOC, Darmstadt, Germany.

Zumberge JF, Heflin MB, Jefferson DC, Watkins MM, Webb FH (1997) Precise Point Positioning for the efficient and robust analysis of GPS data from large networks. Journal of Geophysical Research: Solid Earth 102(B3):5005-17. https://doi.org/10.1029/96JB03860 


\section{APPENDIX}

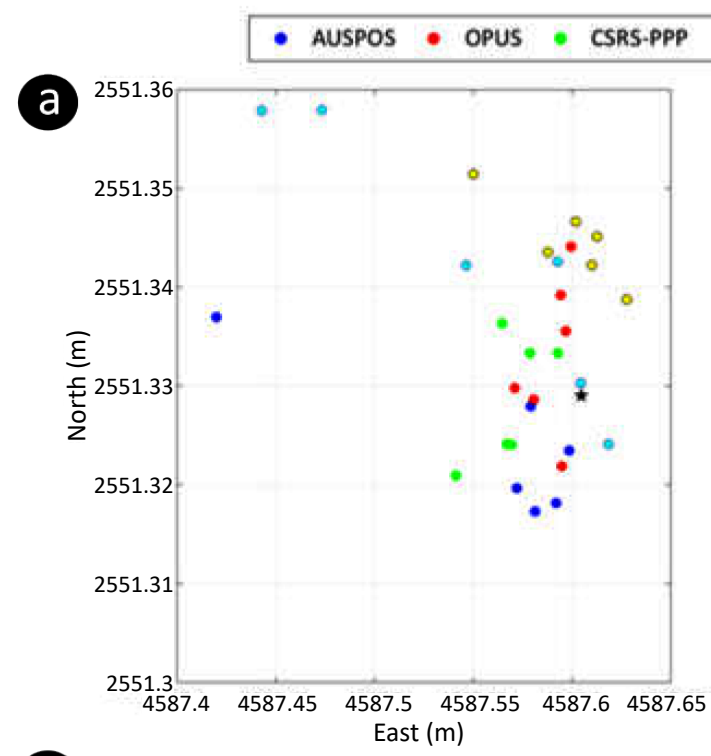

(b)
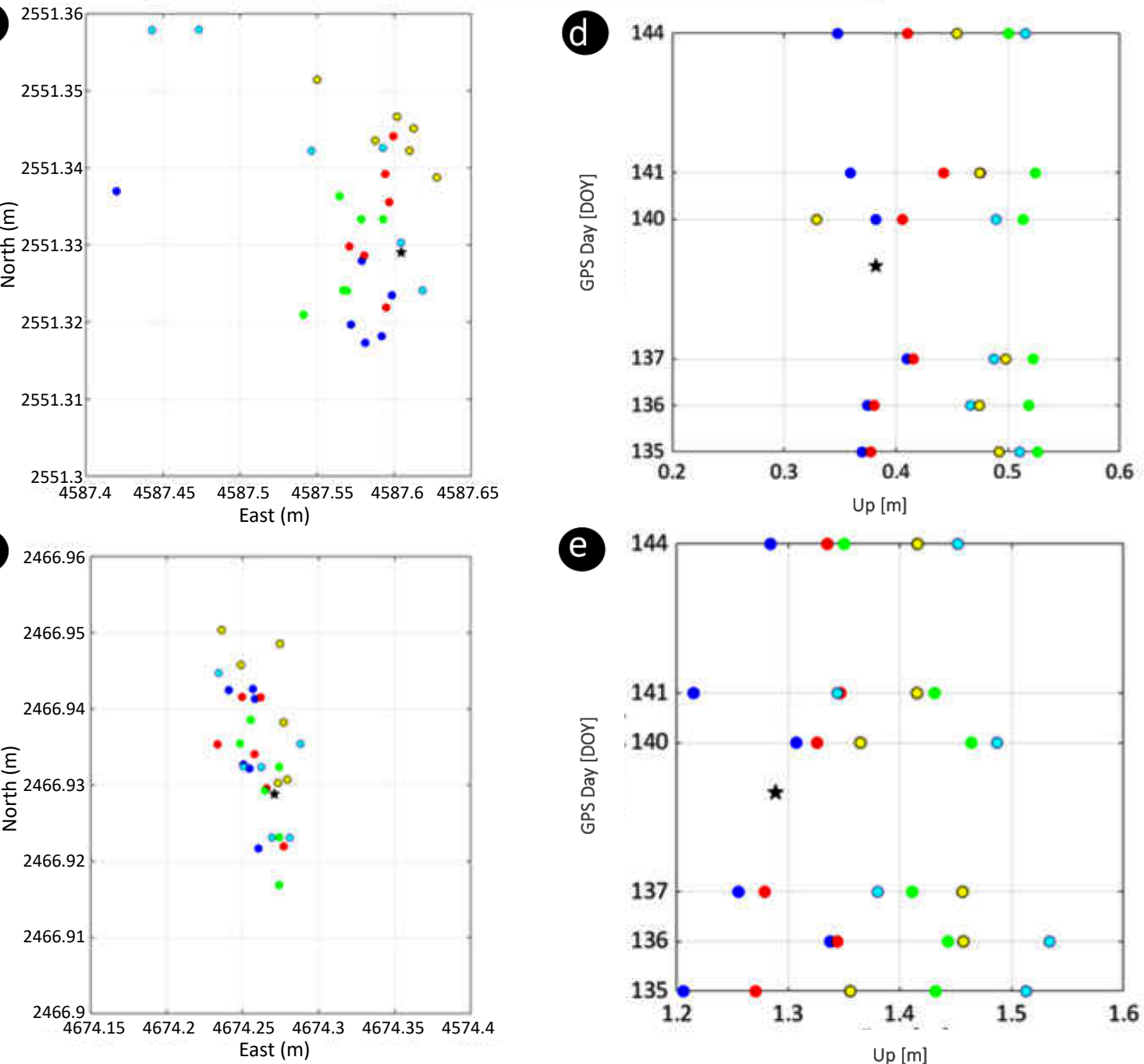

e
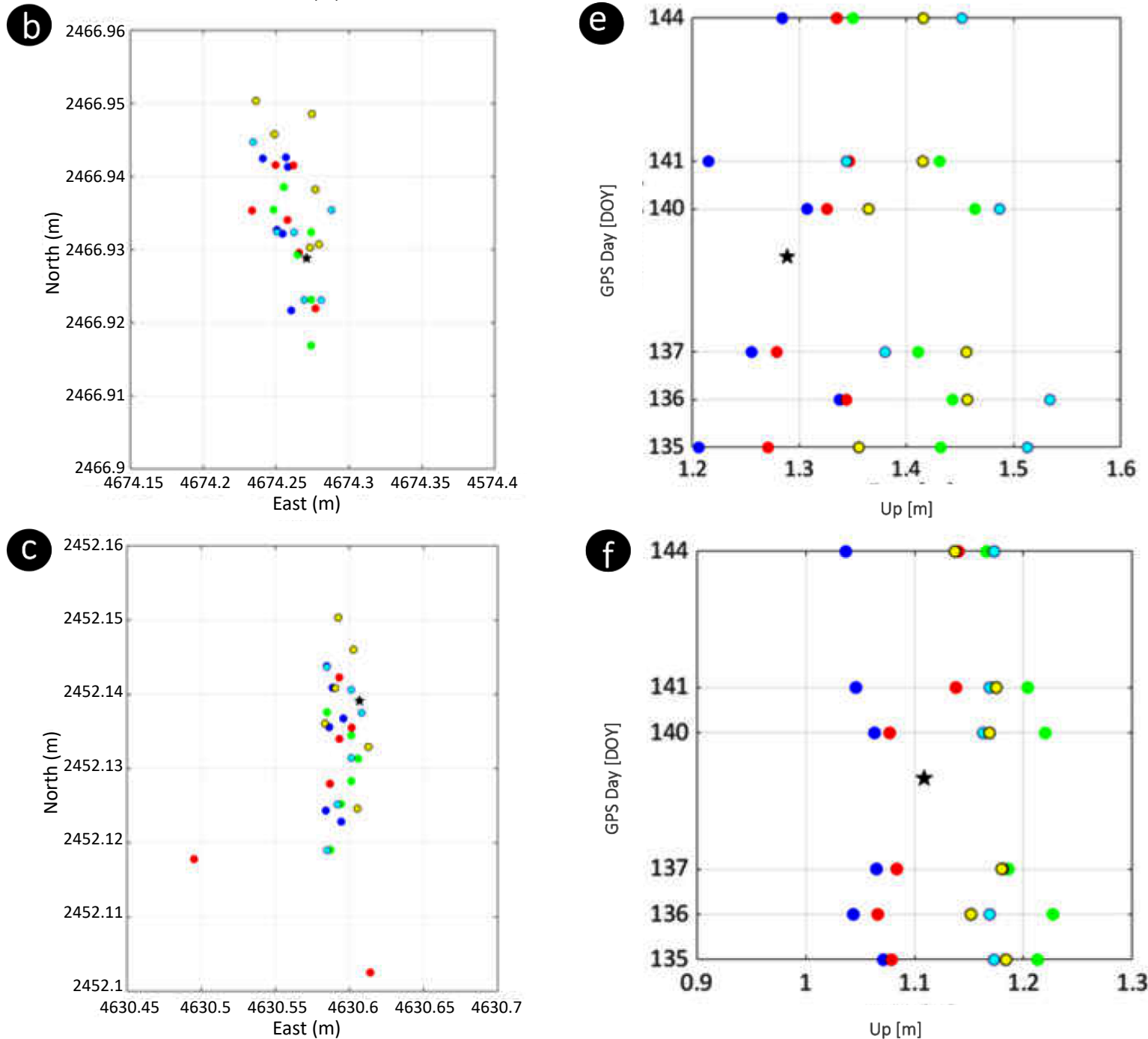

Figure A1: $(\mathbf{a}, \mathbf{b}, \mathbf{c})$ The average of the Bernese coordinates and the 6-day WB services coordinates for the horizontal (North and East) components are shown for P101, P102 and P103, respectively. (d, e, f) The average of the Bernese coordinates and the 6-day WB services coordinates for the vertical components (Up) are shown with the GPS days

(DoY: 135, 136, 137, 140, 141 and 144) for P101, P102 and P103, respectively [ITRF2008 reference frame] 